\title{
The Influence of Machining Parameters on Surface Roughness of MDF in Milling Operation
}

\author{
Ümmü K. İşleyen ${ }^{\mathrm{a}, *}$ and Mehmet Karamanoğlu ${ }^{\mathrm{b}}$ \\ This paper examined the effect of machining parameters on surface \\ roughness of medium density fiberboard (MDF) machined using a \\ computer numerical control (CNC) router. The machining parameters \\ such as spindle speed, feed rate, depth of cut, and tool diameter were \\ examined for milling. The experiments were conducted at two levels \\ of spindle speeds, four levels of feed rates, two levels of tool \\ diameters, and two levels of axial depths of cut. The surface \\ roughness values of MDF grooved by CNC were measured with \\ stylus-type equipment. Statistical methods were used to determine the \\ effectiveness of the machining parameters on surface roughness. The \\ influence of each milling parameter affecting surface roughness was \\ analyzed using analysis of variance (ANOVA). The significant \\ machining parameters affecting the surface roughness were the feed \\ rate, spindle speed, and tool diameter $(p<0.05)$. There was no \\ significant influence of axial depth of cut on the surface roughness. \\ The surface roughness decreased with increasing spindle speed and \\ decreasing feed rate. The value of surface roughness increased with \\ the increase of tool diameter.
}

Keywords: Surface roughness; Spindle speed; Feed rate; Milling operation

Contact information: a: Department of Forest Industrial Engineering, Kastamonu University; b: Department of Materials and Material Processing Technologies, Kastamonu University, 37100, Kastamonu,Turkey; *Corresponding author: ukaragoz@kastamonu.edu.tr

\section{INTRODUCTION}

The surface quality of wood materials is an important criterion, especially for finishing and surface lamination applications and machining method (i.e., milling, drilling, sanding) in the furniture industry. Moreover, it is necessary to know the machining parameters of optimum surface quality in order to use efficient and cost-effective use of advanced technology machines and to save on the process time. The quality characteristics of the machined surfaces are determined by the surface roughness parameters (Davis 1962). Several approaches have been proposed to determine surface roughness, and the first surface roughness measurements were conducted using sensory methods. Because sensory methods are very subjective, the contact (stylus type of profilometer) and non-contact (laser or ultrasonic systems) measurement methods have been proposed for measurement of surface roughness (Funck et al. 1992; Hizıroğlu 1996). In recent years, atomic force microscopy (AFM) and scanning electron microscopy (SEM) methods have been used to evaluate the surface properties of machined materials (Haq and Srivastava 2016). In addition, the optimization approaches such as genetic algorithm (GA), response surface method (RSM), and desirability function (DF) have been used to estimate optimum machining parameters, which make it possible to achieve a minimum surface roughness value (Hazir et al. 2018). 
The surface quality of wood and wood-based materials depends on the parameters associated with material properties (i.e., wood species, anatomical properties, moisture content, density), machining parameters (i.e., spindle speed, cutting force, feed rate, axial depth of cut), and cutting tool properties (i.e., tool wear, diameter, tool geometry) (Coelho et al. 2008; Magos 2008). In the milling of gypsum fiber composite, the effect of the processing parameters such as spindle speed, feed rate, and depth of cut on the cutting force has been optimized by RSM based on a mathematical model (Li et al. 2017). General standards and recommendations have been used due to the lack of a standardized method for determining the surface roughness of wood, medium density fiberboard (MDF), or particleboards. This has led to the use of a wide range of measuring instruments and parameters such as filters, filtering cut-off length, measuring length, and measuring resolution (Gurau and Irle 2017).

Previous studies on the surface roughness of wood material have focused on evaluating the effect of material properties such as wood species (Malkoçoğlu and Özdemir 2006), radial and tangential machining direction (Kılıç 2015, 2017), wood density, early wood and latewood ratio (Sadoh and Nakata 1987; Malkoçoğlu 2007; Zhong et al. 2013), and fiber direction (Mitchell and Lemaster 2002; Iskra and Tanaka 2005; Sütcü 2013). Moreover, the effects of computer numerical control (CNC) machining parameters such as spindle speed, feed rate, and cutting depth on the surface quality of wood have been monitored (Sütçü and Karagöz 2013; Koc et al. 2017; Sofuoglu 2017). CNC machines are widely used in the furniture industry for wood and MDF panels, especially for surface milling. MDF panels must have smooth surfaces for painting and finishing. The effects of machining parameters such as spindle speed, cutting speed, and feed rate on the surface quality of MDF machined with $\mathrm{CNC}$ have been investigated in many studies. Aguilera et al. (2000) reported that surface roughness of CNC machined MDF decreased with increasing material density. Davim et al. (2009) investigated the effect of processing parameters on surface roughness of MDF, which was grooved $5 \mathrm{~mm}$ depth of cut with CNC router, and stated that the surface roughness values decreased at high spindle speed and low feed rate. In another study, Gisip et al. (2009) indicted that the surface quality of MDF machined with the tool wear was decreased. Deus et al. (2015) also revealed that the surface roughness decreased with low depth of cut, high spindle speed, and low feed rate. Sütçü and Karagöz (2012) investigated the effect of machining parameters such as spindle speed, feed rate, stepover, and depth of cut on surface roughness of MDF pocket milling with CNC. They found that surface roughness value increased with increasing feed rate, stepover, and depth of cut and that material removal rate increased with high spindle speed at optimum surface roughness. In another study, the surface roughness of MDF panels has been shown to play an important role in the thin overlay applications such as thin melamine paper or polyvinyl chloride and other decorative overlays on the MDF surface (Aguilera 2000; Hiziroglu and Kosonkorn 2006; Kilıç et al. 2009). At the same time, Li et al. (2018) investigated the surface color change of wood materials machined with a laser machine and found that the color change on the wood surfaces decreased with the increasing of feed speed and sweep width and decreasing of laser power.

As can be seen from the literature studies, the surface quality changes of different materials such as wood and wood based materials, MDF panels under different processing conditions (i.e., milling, drilling, sanding, laser modification) were investigated by different experimental design methods. The differences of this study from other studies are different processing parameters with $\mathrm{CNC}$ router.

The efficiency and accuracy of machining in materials seem to be a very significant 
criterion for the furniture industry. It is important to define the optimum surface machining parameters for the removal of additional sanding costs and labor in surfaces milled with CNC. Therefore, in this study, the effects of machining parameters on surface roughness of MDF panels machined with CNC milling have been examined. The grooving processing was performed on the MDF surfaces using varying processing parameters such as spindle speed, feed rate, depth of cut and tool diameter. The average roughness $\left(R_{\mathrm{a}}\right)$ and mean peak to valley height $\left(R_{\mathrm{z}}\right)$ of surface parameters were evaluated with a stylus type measurement device. The main and interaction effect of machining parameters on surface quality were analyzed by a statistical analysis program.

\section{EXPERIMENTAL}

\section{Materials}

MDF panels of $18 \mathrm{~mm}$ thickness (Kronospan, Kastamonu, Turkey) were used for surface milling. The density values $\left(752 \mathrm{~kg} / \mathrm{m}^{3}\right)$ and moisture content $(7 \%)$ of the MDF panels were evaluated according to EN 323 (1993). MDF profile density value is an important factor affecting surface roughness. The density profiles of the MDF panels were obtained from the manufacturer to determine the effect of the depth of cut and density on the surface roughness. The density profile of MDF is shown in Fig. 1. The surface of the $\mathrm{MDF}$ was grooved with a $\mathrm{CNC}$ router that was used to process the aesthetic pattern, especially on the door surfaces. Two different CNC tools of 4 and $6 \mathrm{~mm}$ diameter were used for grooving. The rake angles of tools are $7^{\circ}$. The tool geometry is presented in Fig. 2a. A total of 36 experimental samples were grooved on MDF panels with a CNC router, as shown in Fig. 2 b.

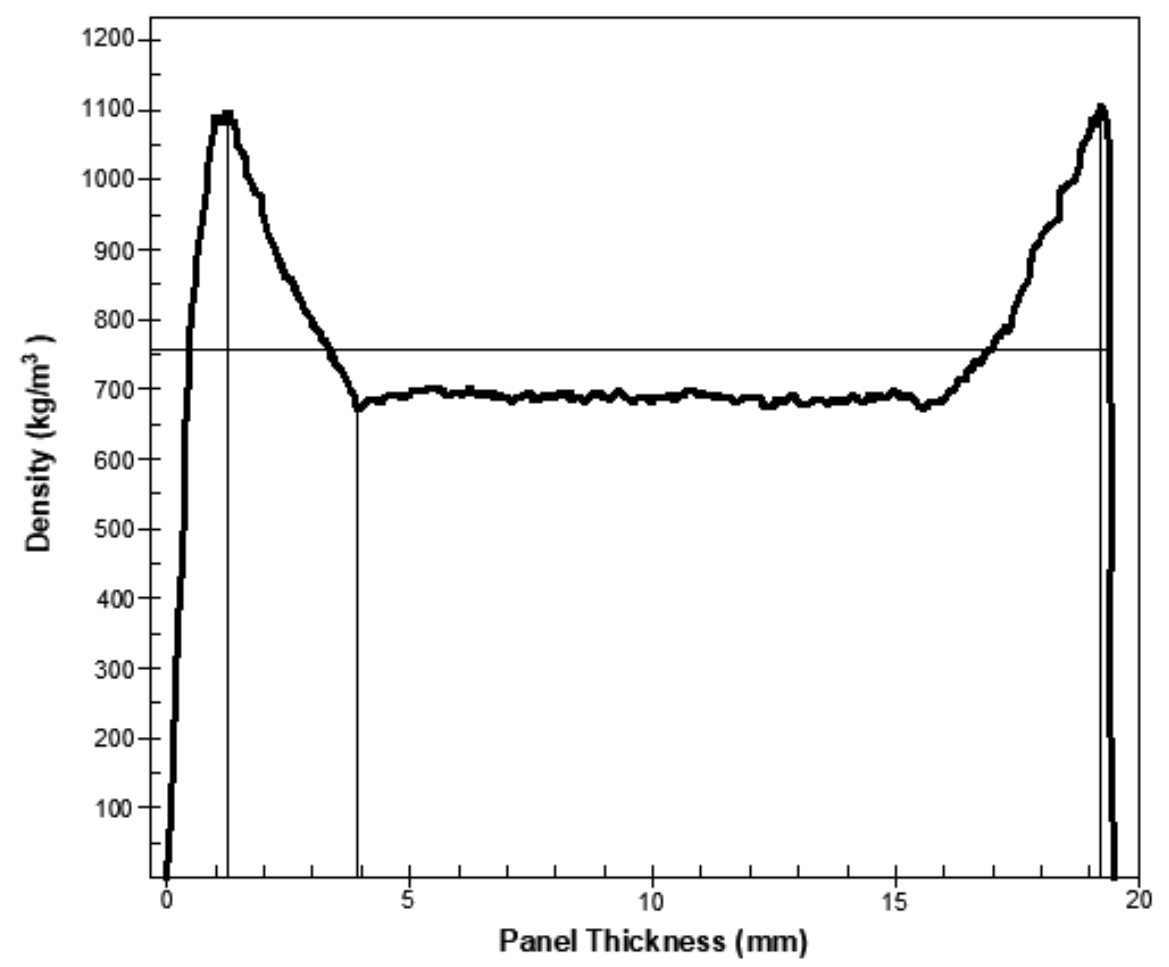

Fig. 1. Density profile of MDF panels 

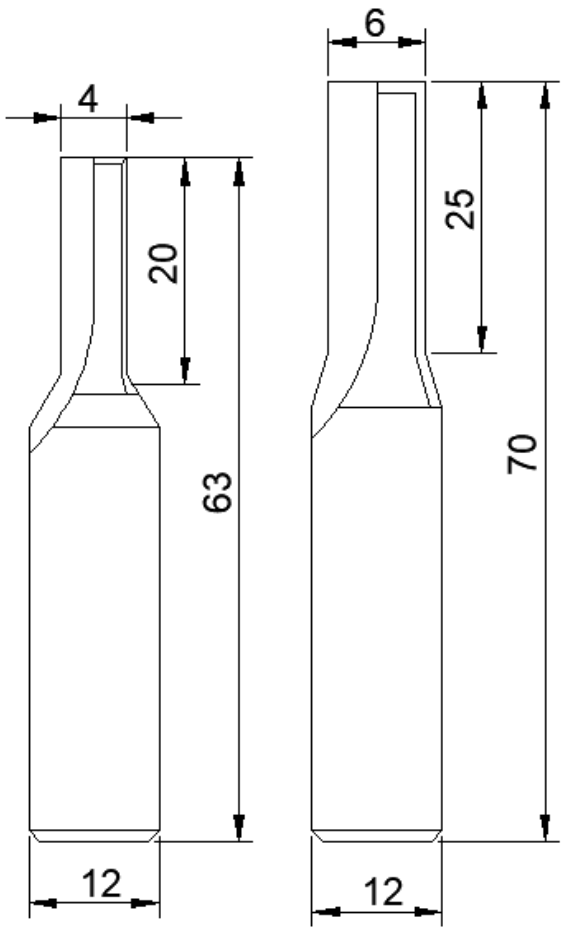

a)

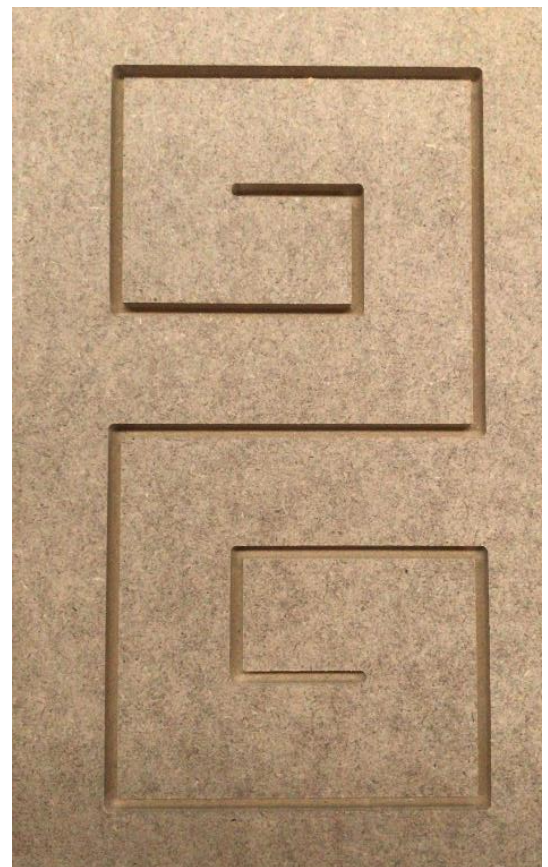

b)

Fig. 2. a) The tool geometry and b) grooved MDF samples

\section{Methods}

Milling parameters such as spindle speed, feed rate, tool diameter, and depth of cut were determined for MDF grooving milling tests, as shown in Table 1.

Table 1. Machining Parameters for MDF Grooving

\begin{tabular}{|c|c|c|c|c|c|}
\hline Parameters & Unit & Level_1 & Level_2 & Level_3 & Level_4 \\
\hline Spindle speed & $\mathrm{rpm}$ & 18000 & 24000 & - & - \\
\hline Feed rate & $\mathrm{mm} / \mathrm{min}$ & 2500 & 5000 & 7500 & 10000 \\
\hline Depth of cut & $\mathrm{mm}$ & 4 & 6 & - & - \\
\hline Tool Diameter & $\mathrm{mm}$ & 4 & 6 & - & - \\
\hline
\end{tabular}

Surface roughness was measured with a Handysurf E-35 measurement equipment (Tokyo, Japan) based on stylus technique (Fig. 3). Roughness measurement was performed from 10 different points on each samples. The average roughness $\left(R_{\mathrm{a}}\right)$ and mean peak to valley height $\left(R_{\mathrm{z}}\right)$ are considered roughness parameters and characterized by ISO 4287 (1997). The tip diameter was $5 \mu \mathrm{m}$, and the measuring force was $4 \mathrm{mN}$. The surface roughness parameter was measured over a length of $1.25 \mathrm{~mm}$ and cut-off length of 0.25 $\mathrm{mm}$. Experimental data of surface roughness was analyzed statistically using analysis of variance (ANOVA), which was performed at the confidence level of $95 \%$. The parameters having a $\mathrm{p}$-value less than $0.05(\mathrm{p}<0.05)$ were considered significant. The difference between the levels of the parameters with significant value $(p<0.05)$ was determined by the t-test and Duncan test. 


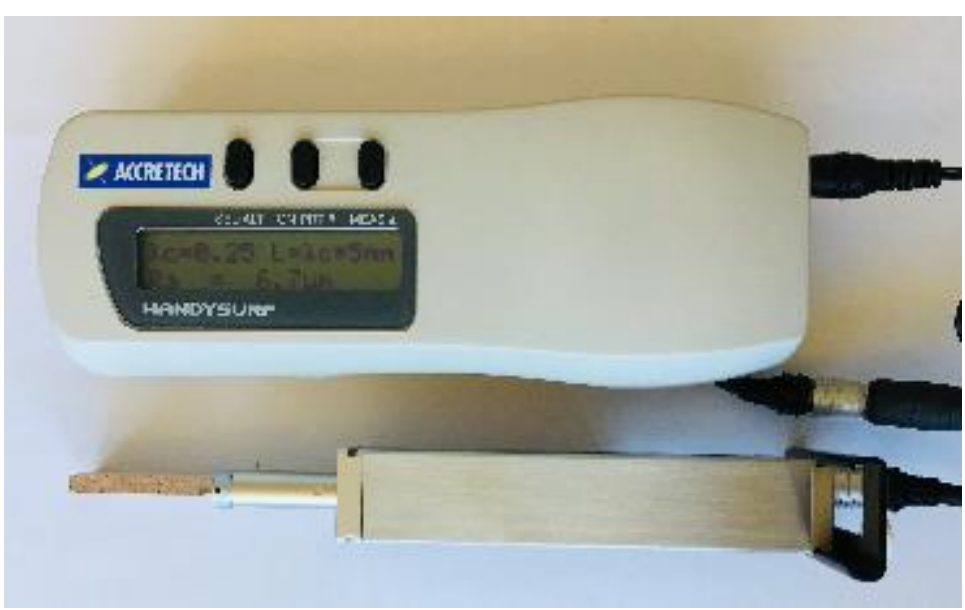

Fig. 3. The surface roughness measurement system

\section{RESULTS AND DISCUSSION}

In this study, experiments were performed to determine the effects of milling parameters on surface roughness. Four different machining parameters (such as spindle speed, feed rate, tool diameter, dept. of cut) were selected for grooving on MDF with CNC router. A total of 32 experimental elements were produced and surface roughness was measured. Before the statistical analysis, a One-Sample Kolmogorov-Smirnov Test indicated that the surface roughness measurement data showed a normal distribution. The main and interaction effects of machining parameters on surface roughness values were analyzed with variance analysis (ANOVA) at a 95\% confidence level. Table 2 and Table 3 present main and interaction effects of machining parameters on surface parameters $R_{\mathrm{a}}$ and $R_{\mathrm{z}}$, respectively.

Table 2. Result of the ANOVA for $R_{a}$

\begin{tabular}{|c|c|c|c|c|c|}
\hline Source & DF & SS & MS & $F$-value & Sig. \\
\hline Spindle Speed A & 1 & 5.118 & 5.118 & 7.815 & $0.006^{*}$ \\
\hline Feed Rate_B & 3 & 15.674 & 5.225 & 7.978 & $0.000^{*}$ \\
\hline Depth of cut_C & 1 & 0.228 & 0.228 & 0.349 & 0.555 \\
\hline Tool diameter_D & 1 & 3.380 & 3.380 & 5.162 & $0.024^{*}$ \\
\hline$A^{*} B$ & 3 & 0.432 & 0.144 & 0.220 & 0.883 \\
\hline$A^{*} \mathrm{C}$ & 1 & 0.018 & 0.018 & 0.027 & 0.869 \\
\hline$A^{*} D$ & 1 & 0.660 & 0.660 & 1.007 & 0.316 \\
\hline $\mathrm{B}^{*} \mathrm{C}$ & 3 & 4.705 & 1.568 & 2.395 & 0.069 \\
\hline$B^{*} D$ & 3 & 2.138 & 0.713 & 1.088 & 0.354 \\
\hline$C * D$ & 1 & 0.284 & 0.284 & 0.433 & 0.511 \\
\hline$A^{*} B^{\star} C$ & 3 & 1.462 & 0.487 & 0.744 & 0.527 \\
\hline$A^{*} B^{*} D$ & 3 & 1.907 & 0.636 & 0.971 & 0.407 \\
\hline$A^{*} C^{*} D$ & 1 & 1.492 & 1.492 & 2.278 & 0.132 \\
\hline$B^{\star} C^{\star} D$ & 3 & 3.466 & 1.155 & 1.764 & 0.154 \\
\hline$A^{\star} B^{*} C^{\star} D$ & 3 & 1.548 & 0.516 & 0.788 & 0.501 \\
\hline Error & 288 & 188.607 & 0.655 & & \\
\hline Total & 320 & 10600.009 & & & \\
\hline Corrected Total & 319 & 231.121 & & & \\
\hline
\end{tabular}


There were significant effects of the spindle speed, feed rate, and tool diameter parameters on the $R_{\mathrm{a}}$ value and $R_{\mathrm{z}}$ at a confidence level of $95 \%$ (Tables 2 and 3 ). The depth of cut had no significant influence on surface roughness (i.e., $R_{\mathrm{a}}$ and $R_{\mathrm{z}}$ ). There was no significant interaction between the model parameters (Tables 2 and 3 ).

Table 3. Result of the ANOVA for $R_{z}$

\begin{tabular}{|l|c|c|c|c|c|}
\hline Source & DF & SS & MS & F-value & Sig. \\
\hline Spindle Speed_A & 1 & 189.682 & 189.682 & 10.114 & $0.002^{*}$ \\
\hline Feed Rate_B & 3 & 351.119 & 117.040 & 6.241 & $0.000^{*}$ \\
\hline Depth of cut_C & 1 & 3.438 & 3.438 & 0.183 & 0.669 \\
\hline Tool diameter_D & 1 & 120.651 & 120.651 & 6.433 & $0.012^{*}$ \\
\hline $\mathrm{A}^{*} \mathrm{~B}$ & 3 & 16.875 & 5.625 & 0.300 & 0.825 \\
\hline $\mathrm{A}^{*} \mathrm{C}$ & 1 & 31.356 & 31.356 & 1.672 & 0.197 \\
\hline $\mathrm{A}^{*} \mathrm{D}$ & 1 & 40.677 & 40.677 & 2.169 & 0.142 \\
\hline $\mathrm{B}^{*} \mathrm{C}$ & 3 & 126.655 & 42.218 & 2.251 & 0.083 \\
\hline $\mathrm{B}^{*} \mathrm{D}$ & 3 & 44.833 & 14.944 & 0.797 & 0.496 \\
\hline $\mathrm{C}^{*} \mathrm{D}$ & 1 & 23.866 & 23.866 & 1.273 & 0.260 \\
\hline $\mathrm{A}^{*} \mathrm{~B}^{*} \mathrm{C}$ & 3 & 34.675 & 11.558 & 0.616 & 0.605 \\
\hline $\mathrm{A}^{*} \mathrm{~B}^{*} \mathrm{D}$ & 3 & 41.559 & 13.853 & 0.739 & 0.530 \\
\hline $\mathrm{A}^{*} \mathrm{C}^{*} \mathrm{D}$ & 1 & 0.911 & 0.911 & 0.049 & 0.826 \\
\hline $\mathrm{B}^{*} \mathrm{C}^{*} \mathrm{D}$ & 3 & 35.587 & 11.862 & 0.633 & 0.595 \\
\hline $\mathrm{A}^{*} \mathrm{~B}^{*} \mathrm{C}^{*} \mathrm{D}$ & 3 & 13.563 & 4.521 & 0.241 & 0.868 \\
\hline Error & 288 & 5401.280 & 18.754 & & \\
\hline Total & 320 & 253768.290 & & & \\
\hline Corrected Total & 319 & 6476.725 & & & \\
\hline DF: Degrees of freedom, SS: Sum of squares, MS: Mean square, ${ }^{*}: \mathrm{p}<0.05$ & &
\end{tabular}

To examine the effects of levels of these machining parameters, t-tests were utilized to determine whether the differences associated with the two spindle speed factors $(18000$ and $24000 \mathrm{rpm})$ and two tool diameter factors $(4$ and $6 \mathrm{~mm})$ were significant. The t-test results for the effect of spindle speed and tool diameter on the surface roughness are presented in Table 4. The effects of spindle speed and tool diameter levels on surface roughness were different. The surface roughness value $\left(R_{\mathrm{a}}=5.82 \mu \mathrm{m}\right)$ at a spindle speed of $18000 \mathrm{rpm}$ was higher than the surface roughness value $\left(R_{\mathrm{a}}=5.565 \mu \mathrm{m}\right)$ at a spindle speed of $24000 \mathrm{rpm}$ (Table 4). This result suggested that the surface roughness decreased with increasing spindle speed. The surface roughness values increased as the tool diameter increased. The surface roughness value $\left(R_{\mathrm{a}}=5.795 \mu \mathrm{m}\right)$ at a tool diameter of $6 \mathrm{~mm}$ was higher than the surface roughness $\left(R_{\mathrm{a}}=5.589 \mu \mathrm{m}\right)$ at a tool diameter of $4 \mathrm{~mm}$ (Table 4$)$.

Table 4. Results of the $t$-test for Spindle Speed and Tool Diameter Level

\begin{tabular}{|c|l|l|l|l|l|l|}
\hline Parameters & Level & $\mathrm{N}$ & Mean & SS & $t$ test & $\mathrm{P}$ \\
\hline Spindle Speed & 18000 & 160 & 5.818 & 0.838 & 0.627 & 0.008 \\
\cline { 2 - 8 } & 24000 & 160 & 5.565 & 0.848 & & \\
\hline \multirow{2}{*}{ Tool Diameter } & 4 & 160 & 5.589 & 0.73401 & 11.689 & \\
\cline { 2 - 8 } & 6 & 160 & 5.795 & 0.94528 & & 0.031 \\
\hline
\end{tabular}

The effects of four different feed rate levels $(2500,5000,7500$, and $10000 \mathrm{~mm} / \mathrm{min})$ on surface roughness values were determined by the Duncan test, and the results are summarized in Table 5 . There was no statistically significant difference between the effects of feed rate level $1(2500 \mathrm{~mm} / \mathrm{min})$, level $2(5000 \mathrm{~mm} / \mathrm{min})$, and level $3(7500 \mathrm{~mm} / \mathrm{min})$ 
on the surface roughness, while level $4(10000 \mathrm{~mm} / \mathrm{min})$ of feed rate was significantly different than the remaining levels (Table 5). The highest surface roughness value was obtained with feed rate of $10000 \mathrm{~mm} / \mathrm{min}\left(R_{\mathrm{a}}=6,057 \mu \mathrm{m}\right)$, while the lowest surface roughness value was obtained with feed rate of $2500 \mathrm{~mm} / \mathrm{min}\left(R_{\mathrm{a}}=5,486 \mu \mathrm{m}\right)$. The effects of the machining parameters on the mean surface roughness values are shown in Fig. 4. The surface roughness value increased with increasing feed rate and tool diameter and with decreasing spindle speed. The effect of the depth of cut parameter on the surface roughness value was negligible because of the same density in the profile area. Although the surface roughness decreased with increasing feed rate, the illustration shows that the average $R_{\mathrm{a}}$ value decreased slightly at $7500 \mathrm{~mm} / \mathrm{min}$ of feed rate. This can be explained by the interaction effect of the tool diameter-feed rate. The interaction effects of machining parameters on the surface roughness are presented in Fig. 5. The interaction effect of spindle speed-feed rate, tool diameter-feed rate, and spindle speed-tool diameter feed influenced the surface roughness. However, the interaction effect of machining parameters was not significant. From the effect of dual interactions graph of spindle speed- feed rate, the surface roughness is found to be minimal at high spindle speed (24000 rpm) with low feed rate $(2500 \mathrm{~mm} / \mathrm{min})$. In addition, the friction, machining force, and contact area between the cutting tool and the workpiece increases with the increased feed rate. Further, higher spindle speed means higher tooth passing frequencies and provides shorter plane area/reduction in chip thickness and hence the machining force and surface roughness decreases (Sarıkaya and Güllü 2014). The surface roughness is found to be minimal at high cutting speed with low feed rate. According to tool diameter- feed rate interaction, the high surface roughness occurred with an increase in tool diameter and feed rate. The reason for the high roughness can be explained with the increasing feed rate and tool diameter, causing vibration and a temperature rise between the work piece and the cutting tool (Suresh et al. 2012). The surface roughness values of the machined samples with $4 \mathrm{~mm}$ of tool diameter and $7500 \mathrm{~mm} / \mathrm{min}$ of feed rate were observed, according to the processing conditions of $4 \mathrm{~mm}$ tool diameter and $5000 \mathrm{~mm} / \mathrm{min}$ feed rate. However, with the increase in tool diameter $(6 \mathrm{~mm})$, the $5000 \mathrm{~mm} / \mathrm{min}$ of feed rate provided a smoother surface quality than $7500 \mathrm{~mm} / \mathrm{min}$ of feed rate. The effect of dual interaction graph of spindle speed-tool diameter shows that the surface roughness decreased with increasing spindle speed and decreasing tool diameter. Also, the best surface roughness was observed at a small tool diameter $(4 \mathrm{~mm})$ and a high spindle speed $(24000 \mathrm{rpm})$. Compared to the surface roughness values with different spindle speeds (18000 rpm and $24000 \mathrm{rpm})$ at 4 and $6 \mathrm{~mm}$ of depth of cut, the lowest roughness value was provided at $2400 \mathrm{rpm}$ of spindle speed and $4 \mathrm{~mm}$ of depth of cut.

Table 5. Results of the Duncan Test for Feed Rate Levels

\begin{tabular}{|c|l|l|l|}
\hline Feed_rate $(\mathrm{mm} / \mathrm{min})$ & $N$ & Mean & HG \\
\hline 2500 & 80 & 5.486 & $\mathrm{a}$ \\
\hline 7500 & 80 & 5.550 & $\mathrm{a}$ \\
\hline 5000 & 80 & 5.676 & $\mathrm{a}$ \\
\hline 10000 & 80 & 6.057 & $\mathrm{~b}^{*}$ \\
\hline
\end{tabular}

HG: Homogenous group *: The highest surface roughness value 


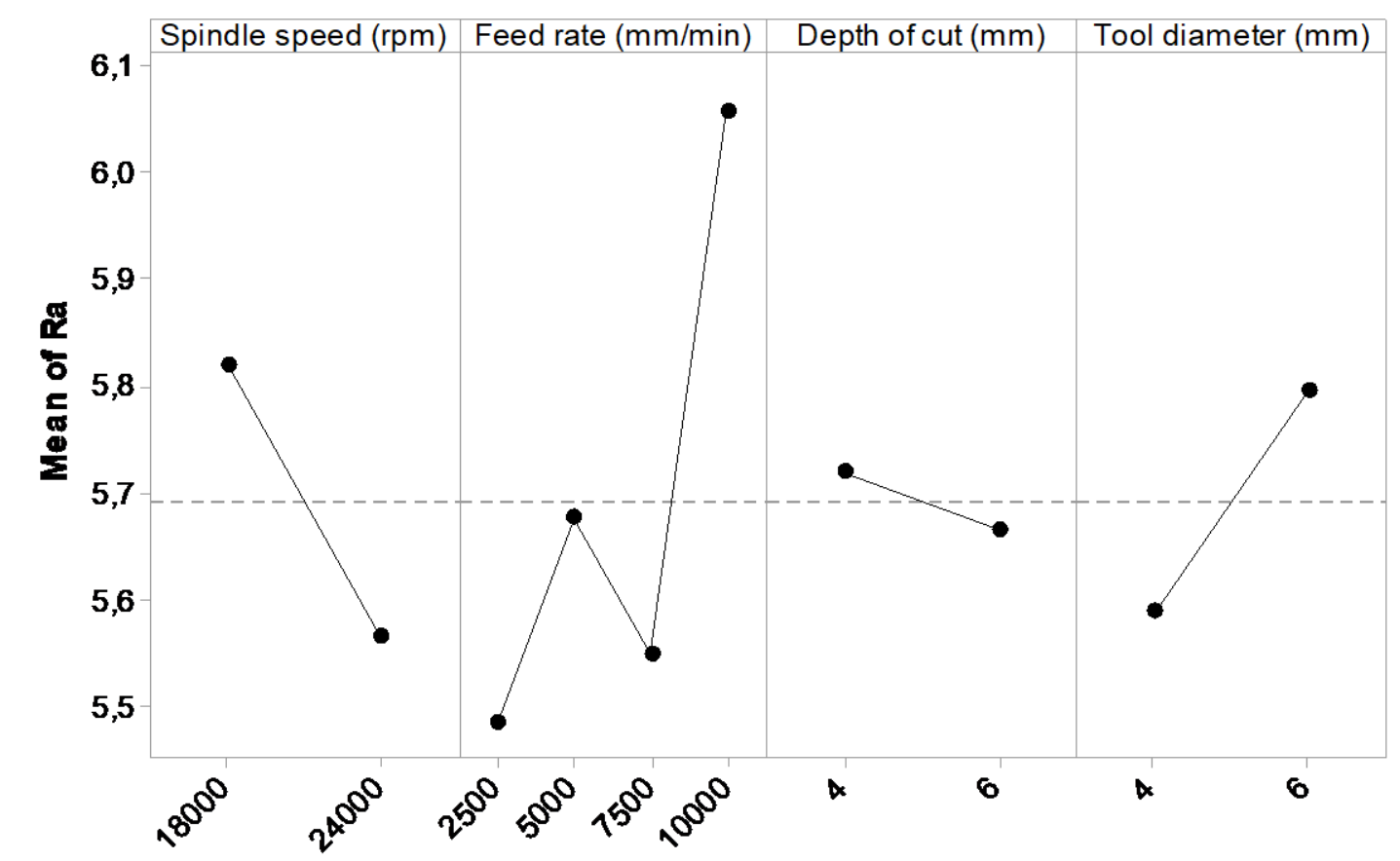

Fig. 4. Mean surface roughness values in machining parameters for $R_{a}$

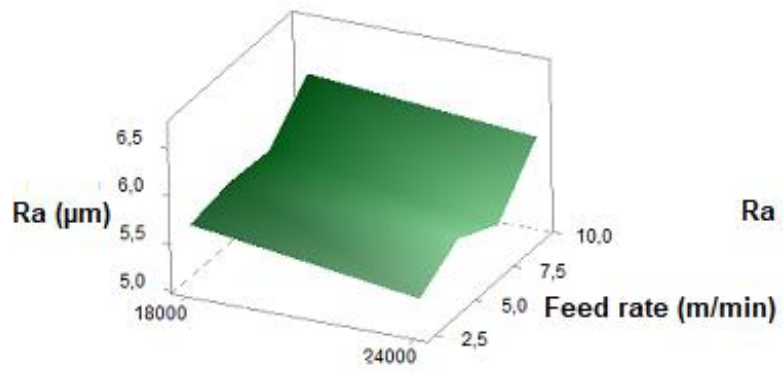

Spindle speed (rpm)

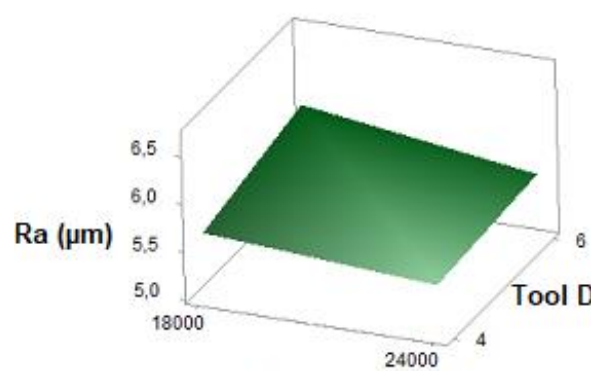

Spindle speed $(\mathrm{rpm})$
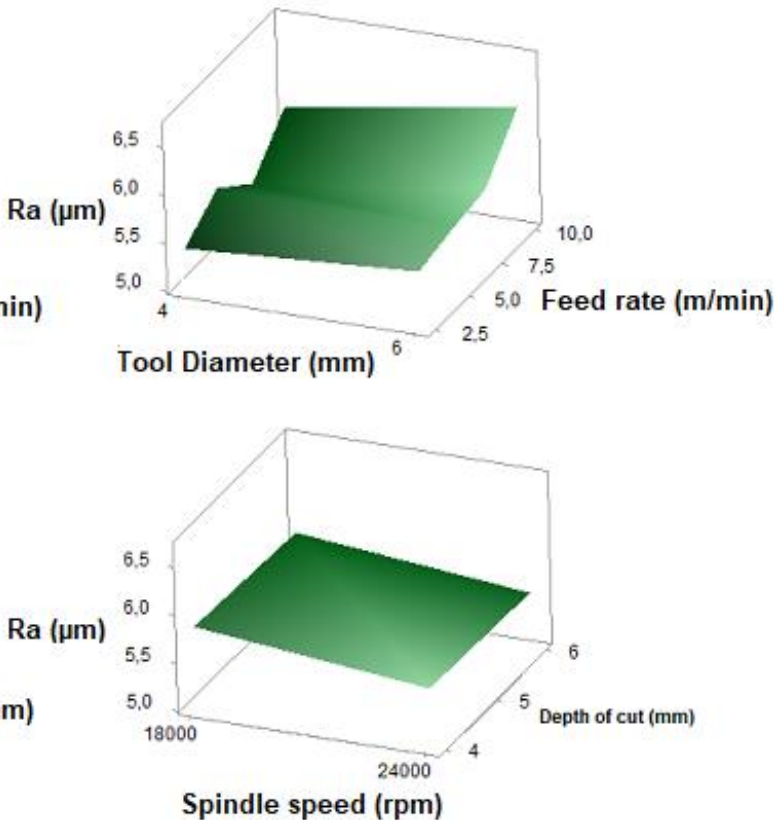

Fig. 5. The surface plots of $R_{a}$ according to interactions effect of machining parameters

The main effects of factors (tool diameter, feed rate, spindle speed) on roughness were statistically significant, although interaction of factors had no effect on surface roughness. Spindle speed was a significant factor affecting surface roughness. The surface roughness decreased with increasing spindle speed. The spindle speed at $24000 \mathrm{rpm}$ 
provided the smallest surface roughness value. The feed rate at $10000 \mathrm{~mm} / \mathrm{min}$ provided the highest surface roughness value, while feed rates of $2500 \mathrm{~mm} / \mathrm{min}, 5000 \mathrm{~mm} / \mathrm{min}$, and $7500 \mathrm{~mm} / \mathrm{min}$ provided similar results. The $4 \mathrm{~mm}$ tool diameter provided a lower surface roughness value than the $6 \mathrm{~mm}$ tool diameter. Depending on other machining factors, the roughness increased as the friction area between the material and tool increased with the increasing tool diameter. Previous studies indicated that the surface roughness decreases with increasing spindle and decreasing feed rate (Davim et al. 2009; Sütçü 2013; Sütçü and Karagöz 2013; Sofuoglu 2015). The results of this study were consistent with the previous research.

Vertical density profile is one of the most important features that characterize the surface roughness properties of MDF in milling. The vertical density value decreases from the surface layer towards the core layer of MDF (Gupta et al. 2006). Therefore, the increasing the axial depth of the cut increases the roughness because the density of MDF layer decreases. Surface roughness increases with increasing axial depth of cut in MDF milling (Aguilera et al. 2000; Sütçü and Karagöz 2012; Sofuoğlu 2017). Deus et al. (2015) reported that surface roughness of MDF exhibits lower values with $1 \mathrm{~mm}$ depth of cut, higher spindle speeds, and lower feed rates. In this study, the statistical analysis indicated that there was no significant difference between axial depth cuts of 4 and $6 \mathrm{~mm}$. Because the 4 and $6 \mathrm{~mm}$ depth of cut results in the same MDF profile density value, it had no effect on surface roughness (Fig. 1).

\section{CONCLUSIONS}

1. Because depth of cut is same density zone in the MDF vertical density profile, the depth of cut is not an important factor affecting the surface roughness.

2. The increasing the tool diameter increases the cutting temperature, cutting force, and vibration intensity. In addition, tool wear occurs due to friction between the tool and the material. The value of surface roughness increased with the increase of tool diameter. The tool diameter of $6 \mathrm{~mm}$ achieved surface roughness higher than $4 \mathrm{~mm}$ tool diameter.

3. The value of surface roughness decreased with increasing spindle speed. Spindle speed at $24000 \mathrm{rpm}$ were able to produce the best surface roughness in milling operation.

4. The value of surface roughness increased with the increase of feed rate. Feed rate at $10000 \mathrm{~mm} / \mathrm{min}$ provided roughest surface from other feed rate levels $(2500,5000,7500$ rpm).

\section{REFERENCES CITED}

Aguilera, A., Meausoone, P. J., and Martin, P. (2000). "Wood material influence in routing operations: The MDF case," Holz als Roh - und Werkstoff 58, 278-283. DOI: $10.1007 / \mathrm{s} 001070050425$

Coelho, C.L., Carvalho, L. M. H., Martins, J. M., Costa, C. A. V., Daniel, M., and Méausoone, P. J. (2008). "Method for evaluating the influence of wood machining conditions on the objective characterization and subjective perception of a finished 
surface," Wood Science and Technology 42, 181-195. DOI: 10.1007/s00226-0070166-1

Davim, J. P., Clemente V. C., and Silva, S. (2009). "Surface roughness aspects in milling MDF (medium density fibreboard)," The International Journal of Advanced Manufacturing Technology 40, 49-55. DOI: 10.1007/s00170-007-1318-z

Davis, E. M. (1962). Machining and Related Characteristics of United States Hardwoods (Technical Bulletin No. 1267), U.S. Department of Agriculture, Forest Service, Washington, D.C.

Deus, P. R. D., Alves, M. C. S., and Vieira, F. H. A. (2015). "The quality of MDF workpieces machined in CNC milling machine in cutting speeds, feed rate, and depth of cut," Meccanica 50 (12), 2899-2906. DOI: 10.1007/s11012-015-0187-z

EN 323 (1993). "Wood based panels - Determination of density," European Committee for Standardization, Brussels.

Funck, J. W., Forrer, J. B., Buttler, D. A., Brunner, C. C., and Maristany, A. G. (1992). "Measuring surface roughness on wood: A comparison of laser-scatter and stylustracing approaches," The International Society for Optical Engineering (SPIE) 1821, 173-184. DOI: $10.1117 / 12.145533$

Gisip, J., Gazo, R., and Stewart, H. A. (2009). "Effects of cryogenic treatment and refrigerated air on tool wear when machining medium density fiberboard," Journal of Materials Processing Technology 209(2009), 5117-5122. DOI:

10.1016/j.jmatprotec.2009.02.010

Gupta, A., Jordan, P. J., and Pang, S. (2006). "Modelling of vertical density profile of MDF in hot pressing," in: Proceedings of CHEMECA 2006: Knowledge and Innovation, CHEMECA, Auckland, New Zealand, pp. 17-20.

Gurau, L., and Irle, M. (2017). "Surface roughness evaluation methods for wood products: A review," Current Forestry Reports 3, 119-131. DOI: 10.1007/s40725017-0053-4

Haq, S., and Srivastava, R. (2016). "Measuring the influence of materials composition on nano scale roughness for wood plastic composites by AFM," Measurement 91, 541547. DOI: 10.1016/j.measurement.2016.05.095

Hazir, E., Erdinler, E. S., and Koc, K. H. (2018). "Optimization of CNC cutting parameters using design of experiment (DOE) and desirability function," Journal of Forest Research 29(5), 1423-1434. DOI: 10.1007/s11676-017-0555-8

Hızıroğlu, S. (1996). "Surface roughness analysis of wood composites: A stylus method," Forest Products Journal 46(7/8), 67-72.

Hiziroğlu, S., and Kosonkorn, P. (2006). "Evaluation of surface roughness of Thai medium density fiberboard (MDF)," Building and Environment 41(4), 527-533. DOI: 10.1016/j.buildenv.2005.02.016

Iskra, P., and Tanaka, C. (2005). "The influence of wood fiber direction, feed rate, and cutting width on sound intensity during routing," Holz als Roh - und Werkstoff 63(3), 167-172. DOI: 10.1007/s00107-004-0541-7

ISO 4287 (1997). "Geometrical product specifications surface texture profile method terms, definitions and surface texture parameters," International Organization for Standardization, Geneva, Switzerland.

Kılıç, M., Burdurlu, E., Aslan, S., Altun, S., and Tümerdem, Ö. (2009). "The effect of surface roughness on tensile strength of the medium density fiberboard (MDF) overlaid with polyvinyl chloride (PVC)," Materials and Design 30, 4580-4583. DOI: 10.1016/j.matdes.2009.03.029 
Kiliç, M. (2017). "Determination of the surface roughness values of Turkish red pine (Pinus brutia (Ten.)) woods" BioResources 12(1), 1216-1227. DOI: 10.15376/biores.12.1.1216-1227

Kılıç, M. (2015). "Effects of machining methods on the surface roughness values of Pinus nigra Arnold wood," BioResources 10(3), 5554-5562. DOI:

10.15376/biores.10.3.5554-5562

Koc, K. H., Erdinler, E. S., Hazir, E., and Öztürk, E. (2017). "Effect of CNC application parameters on wooden surface quality," Measurement 107, 12-18. DOI: 10.1016/j.measurement.2017.05.001

Li, R., Cao, P., Zhang, S., Xu, W., Ekevad, M., and Guo, X. (2017). "Prediction of cutting force during gypsum fiber composite milling process using response surface methodology," Wood and Fiber Science 49(4), 453-460.

Li, R., Xu, W., Wang, X., and Wang, C. (2018). "Modeling and predicting of the color changes of wood surface during CO2 laser modification," Journal of Cleaner Production 183, 818-823. DOI: 10.1016/j.jclepro.2018.02.194.

Magos, E. (2008). "General regularities of wood surface roughness," Acta Silv. Lign. Hung. 4, 81-93.

Malkoçoğlu, A., and Özdemir, T. (2006). "The machining properties of some hardwoods and softwoods naturally grown in eastern black sea region of Turkey," Journal of Materials Processing Technology 173 (3), 315-320. DOI: 10.1016/j.jmatprotec.2005.09.031

Malkoçoğlu, A. (2007). "Machining properties and surface roughness of various wood species planed in different conditions," Building and Environment 42, 2562-2567. DOI: 10.1016/j.buildenv.2006.08.028

Mitchell, P., and Lemaster, R. (2002). "Investigation of machine parameters on the surface quality in routing soft maple," Forest Products Journal 52(6), 85-90.

Sadoh, T., and Nakato, K. (1987). "Surface properties of wood in physical and sensory aspects," Wood Science and Technology 21, 111-120. DOI: 10.1007/BF00376191

Sarıkaya, M., and Güllü, A. (2014). "Taguchi design and response surface methodology based analysis of machining parameters in CNC turning under MQL," Journal of Cleaner Production 65, 604-616. DOI: 10.1016/j.jclepro.2013.08.040

Sofuoglu, S. D. (2015). "Determination of optimal machining parameters of massive wooden edge-glued panels made of European larch (Larix decidua Mill.) using Taguchi design method," BioResources 10(4), 7772-7781. DOI: 10.15376/biores.10.4.7772-7781

Sofuoglu, S. D. (2017). "Determination of optimal machining parameters of massive wooden edge glued panels which is made of Scots pine (Pinus sylvestris L.) using Taguchi design method," European Journal of Wood and Wood Products 75, 33-42. DOI: $10.1007 / \mathrm{s} 00107-016-1028-\mathrm{z}$

Suresh, R., Basavarajappa, S., Gaitonde, V. N., and Samuel, G. L. (2012). "Machinability investigations on hardened AISI 4340 steel using coated carbide insert," International Journal of Refractory Metals and Hard Materials 33, 75-86. DOI: 10.1016/j.ijrmhm.2012.02.019

Sütçü, A. (2013). "Investigation of parameters affecting surface roughness in CNC routing operation on wooden EGP," BioResources 8(1), 795-805. DOI: 10.15376/biores.8.1.795-805

Sütçü, A., and Karagöz, Ü. (2012). "Effect of machınıng parameters on surface quality after face milling of MDF," Wood Research 57(2), 231-240. 
Sütçü, A., and Karagöz, Ü. (2013). "The influence of process parameters on the surface roughness in aesthetic machining of wooden edge-glued panels (EGPs)," BioResources 8(4), 5435-5448. DOI: 10.15376/biores.8.4.5435-5448

Zhong, Z. W., Hiziroglu, S., and Chan, C. T. M. (2013). "Measurement of the surface roughness of wood based materials used in furniture manufacture," Measurement 46(4), 1482-1487. DOI: 10.1016/j.measurement.2012.11.041

Article submitted: January 10, 2019; Peer review completed: February 12, 2019; Revised version received: February 27, 2019; Accepted: February 28, 2019; Published: March 4, 2019.

DOI: $10.15376 /$ biores.14.2.3266-3277 